\title{
Verteporfin can Reverse the Paclitaxel Resistance Induced by YAP Over-Expression in HCT-8/T Cells without Photoactivation through Inhibiting YAP Expression
}

\author{
Wang Pana Qian Wanga Yi Zhanga Naishu Zhanga Jiamin Qina Wei Lia \\ Jing Wang ${ }^{a}$ Fangfang Wu ${ }^{a}$ Lingsen $\mathrm{CaO}^{\mathrm{a}}$ Guanglin $\mathrm{Xu}_{\mathrm{u}^{\mathrm{a}, \mathrm{b}, \mathrm{c}}}$ \\ aDepartment of the College of Life Sciences, Nanjing Normal University, Nanjing, bJiangsu Key \\ Laboratory of 3D Printing Equipment and Manufacturing, Nanjing Normal University, 'Jiangsu Key \\ Laboratory for Molecular and Medical Biotechnology, College of Life Science, Nanjing Normal \\ University, Nanjing, China
}

\section{Key Words}

Paclitaxel • Drug resistance $\cdot$ YAP $・$ Verteporfin $•$ Combination therapy $・$ Colon cancer

\begin{abstract}
Background/Aims: Paclitaxel (PTX) is one of the most effective anti-cancer drugs. However, multiple drug resistance is still the main factor that hinders the effective treatment of cancer with PTX. Several factors including YAP over-expression can cause PTX resistance. In this study, we aimed to verify the role YAP plays in PTX resistance, explore the reversal of PTX resistance by verteporfin (VP) and investigate the effect of combination therapy of PTX and VP on the PTX resistant colon cancer cells (HCT-8/T). Methods: To study the relationship between YAP and PTX resistance, a stable YAP-over-expression or YAP silencing cell line was generated by transfected with YAP-plasmids or siYAP-RNA. WST-1 assay was performed to detect the cytotoxicity of PTX on HCT-8 and HCT-8/T cells. Clone formation assay and Transwell assay was preformed to determine the cell proliferation and invasion ability respectively. Immunofluorescence and Western blot analysis was performed for protein detection. Results: YAP was stronger expressed in HCT-8/T than in HCT-8, and PTX resistance was positively correlated with the level of YAP expression. VP, a strongly YAP inhibitor, could reduce the PTX resistance on HCT-8/T cells without light activation by inhibiting YAP. Beside, VP and PTX combination therapy showed synergism on inhibition of YAP and cytotoxicity to HCT-8/T. Moreover, verteporfin and PTX combination therapy affect the invasion and colony formation ability and induce apoptosis of HCT-8/T cells. Conclusions: VP can reverse the PTX resistance induced by YAP over-expression in HCT-8/T cells without photoactivation through inhibiting YAP expression.
\end{abstract}




\section{Cellular Physiology Cell Physiol Biochem 2016;39:481-490 and Biochemistry \begin{tabular}{l|l} 
DOI: 10.1159/000445640 & (c) 2016 The Author(s). Published by S. Karger AG, Basel \\
www.karger.com/cpb
\end{tabular} \\ Pan et al.: Verteporfin can Reverse the Paclitaxel Resistance without Photoactivation through Inhibiting YAP Expression}

\section{Introduction}

Colon cancer is the most frequently malignant tumor that occurs in the human alimentary canal part, males aged between 40 and 50 suffer the highest morbidity [1]. Colon cancer has become one of the top three dangerous in gastrointestinal tumor [2]. The susceptible population includes the patient suffering from chronic colitis, colon polyps [3] and so on. Nowadays, traditional therapies focus on the surgery and chemo, or Chinese medicine treatment [4]. However, total resection of the lesion is not available yet, patients may suffer recrudescence or tumor metastasis. All this remain a challenge for oncologists.

After adriamycin and cisplatin, one of the most effective anti-cancer drugs is PTX which has been deeply researched and widely used to fight against various human cancers [5-7] and is called the last line of cancer-defense. Since it is such a strong and efficient chemotherapy drug, we wondered how to avoid the drug resistance caused by multiple use on the tumor cells [8], which is also a huge obstacle to successful cancer treatments. Colon cancer patients usually have less sensitivity of chemotherapy [9] for several reasons, one is that YAP plays a role in human colon cancer progression.

Hippo-YAP pathway is a signaling pathway which has been found in recent years [10]. It is a kinase cascade that regulates proliferation and apoptosis to control organ size during developmental growth [11]. In tumor cells, YAP is one of the major transcription activation factors and is highly active. Reviewing the study of colon cancer, we found that steinhardt compared 28 colon cancer tissues with 16 normal colon mucosa tissues and found out that YAP is at a obviously higher level in both nuclear and cytoplasm [12]. This suggested that YAP is an oncogene in pathological conditions [13]. Recently, more and more reports indicated that the expression of YAP should also be connected with multi-drug resistance [14]. As a new anti-tubulin drug [15], PTX can raise the binding ability of 14-3-3 protein with YAP while remain the stability of tublins and maintain YAP in phosphorylation status [16]. This leads to the restriction of prevents YAP to of being a transcription factor. However, the inhibition function to YAP of paclitaxel can be reversed by the up-regulation of YAP [17].

Verteporfin (VP), a benzoporphyrin derivative, belongs to the porphyrin family, is clinically used to treat neovascular macular degeneration [18]. Recently studies indicated that VP may inhibit the growth of hepatoma cells without photoactivation through inhibition of YAP-TEAD complex [19]. Therefore, we wondered that whether the inhibition of YAP through VP can reserve the PTX resistance caused by the over-expression of YAP, and this may contribute to the clinical use of PTX.

In this study, we investigated whether the drug resistance of the colon cancer cell subline HCT-8/T, which was already PTX resistant, can be reversed via VP treatment and the YAP inhibition. And the effect of the combination therapy of PTX and VP on HCT-8/T cells was investigated. Our findings suggested that VP could reverse the PTX resistance induced by YAP over-expression in HCT-8/T cells through inhibiting YAP expression. Moreover, the combined treatment with VP and PTX could influence the YAP expression and cell viabilities.

\section{Materials and Methods}

\section{Cells and cell culture}

All cell lines were purchased from the Shanghai Bogoo Biotechnology Co., Ltd. HCT-8 and HCT-8/T cells were cultured in RPMI-1640 medium (Gibco, USA) supplemented with 10\% fetal bovine serum (FBS) (Gibco, USA), $100 \mathrm{U} / \mathrm{mL}$ penicillin, and $100 \mathrm{mg} / \mathrm{mL}$ streptomycin, and were incubated at $37^{\circ} \mathrm{C}$ in $5 \% \mathrm{CO}_{2}$ humidified air. Cells were passaged until reached $90 \%$ confluence.

\section{Determination of drug resistance}

Cells were seeded into 96-well plates (Corning, USA) and grown in RPMI-1640 media for $24 \mathrm{~h}$, subsequently the cells were treated with various concentrations of paclitaxel for $48 \mathrm{~h}$. An aliquot (20 $\mu$ l) of WST-1 solution ( $5 \mathrm{mg} / \mathrm{ml}$ ) was then added to each well and incubated at $37^{\circ} \mathrm{C}$ for $4 \mathrm{~h}$. The optical absorbance 


\section{Cellular Physiology Cell Physiol Biochem 2016;39:481-490 \begin{tabular}{ll|l} 
DOI: 10.1159/000445640 & $\begin{array}{l}\text { O 2016 The Author(s). Published by S. Karger AG, Basel } \\
\text { www.karger.com/cpb }\end{array}$
\end{tabular} \\ Pan et al.: Verteporfin can Reverse the Paclitaxel Resistance without Photoactivation through Inhibiting YAP Expression}

in the wells was determined at $450 \mathrm{~nm}$ using a Synergy ${ }^{\mathrm{TM}} 2$ Multi-function Microplate Reader (Bio-Tek Instruments, Winooski, VT, USA). Each treatment was performed in sextuplicate and each experiment was repeated three times. The half-maximal inhibitory concentration $\left(\mathrm{IC}_{50}\right)$ was defined as the concentration that caused $50 \%$ inhibition of cell proliferation. The resistance factor (RF) was calculated using the following equation: $\mathrm{RF}=\left(\mathrm{IC}_{50}\right.$ of HCT-8/T $) /\left(\mathrm{IC}_{50}\right.$ of HCT-8).

Antibodies, reagents and plasmids

The primary antibodies, anti-YAP (sc-15407) was purchased from Santa-cruz (USA), anti-Cyr61 (11952S), Bcl-2(\#2870S) and BAX (\#2772) were from Cell signaling technology (CST, USA), and anti- $\beta$ actin (BS6007M) was purchased from Bioworld (USA). The secondary antibodies, horseradish peroxidaseconjugated goat anti-rabbit IgG (BS13278) and horseradish peroxidase-conjugated goat anti-mouse IgG (\#7076S) were purchased from CST (USA), and horseradish peroxidase-conjugated goat anti-rabbit IgG (BS13278) was purchased from Bioworld (USA). The secondary antibody, fluorophore-labeled goat antirabbit IgG (ab350077) was purchased from abcam (UK). PTX and VP used in chemotherapeutic drug experiments were purchased from Sigma (USA). YAP-siRNA (sc-38637) was purchased from Santa-cruz (USA). The plasmids used in transfection were purchased from Genloci Biotechnoligies Inc. (China). Control experiments were performed using one set of cells, and then repeated at least three times.

\section{Cell transfection}

To investigate the relationship between YAP and PTX resistance, YAP plasmids and siYAP-RNA was transfected, respectively, into YAP-low/PTX-sensitive HCT-8 cells or YAP-high/PTX-resistance HCT-8/T cells with $30 \mu \mathrm{l}$ Lipofectamine 2000 transfection reagent (Invitrogen, USA) following the manufacturer's instructions. After incubation for $24 \mathrm{~h}$, the transfected cells were used for the following experiments.

\section{Western blot}

Whole-cell protein was obtained using RIPA buffer (Solar Bio, China) containing $1 \mathrm{mM}$ phenylmethanesulfonyl fluoride (PMSF), and equal protein loading of the lysates was achieved by standardization with Spectrophotometer. Samples were separated by electrophoresis on SDS-PAGE gel and transferred to PVDF membranes (Millipore). Membranes were blocked at room temperature for $1 \mathrm{~h}$ in PBS containing $0.1 \%$ Tween- 20 and $5 \%$ fat-free powdered milk, and incubated overnight with primary antibodies (anti- $\beta$-catenin 1:1000, anti-YAP 1:1000, anti-Cyr61 1:1000) at $4^{\circ} \mathrm{C}$, followed by horseradish peroxidase-conjugated secondary antibody $(1: 5000)$ overnight at $4^{\circ} \mathrm{C}$. Protein bands were analyzed using the TS380-H Automatic washing machine (Taixing TaiSheng Medical Equipment Factory, China).

\section{Immunofluorescence}

For immunofluorescence analysis, cells were plated in chamber slides then fixed in methanol (AR) for $10 \mathrm{~min}$ at room temperature, permeabilized with 5\% Bovine serum albumin in PBST. Cells were then exposed to primary antibodies (anti-YAP 1:200 ) diluted in PBST containing 5\% bovine serum albumin overnight at $4^{\circ} \mathrm{C}$. After washing three times with PBS for $10 \mathrm{~min}$, secondary antibody (Alexa Fluor 488goat anti-rabbit 1:200) diluted in PBST was added and incubated for $1 \mathrm{~h}$ at room temperature. Cells were then washed in PBS and mounted using 40,6-diamidino-2-phenylindole to counterstain DNA. Images were collected using a confocal microscope (MRC-1024, Bio-rad, America).

\section{Colony formation assay}

For Colony formation, the cells were seeded into 6-well plates (200 cells per well), and then cells were treated with different concentrations of PTX, VP or PTX + VP for $24 \mathrm{~h}$, followed by incubation at $37^{\circ} \mathrm{C}$ for 9 d. Colonies were fixed with $4 \%$ paraformaldehyde (Solarbio) for 20 minutes and stained with Giemsa stain (Solarbio) for 20 minutes. Then they were washed slowly with running water and air dried naturally. At last, the number of cell clones with more than 50 cells was counted under the microscope.

\section{Cell invasion assay}

A 24-well Transwell chamber was used with a pore size of $8 \mu \mathrm{m}$ (Corning, NY, USA) and the inserts were coated with Matrigel (BD Bioscience) in serum-free medium. Forty-eight hours after transfection, cells were trypsinized and transferred to the upper Matrigel chamber in serum-free medium containing $3 \times 10^{5}$ 


\section{Cellular Physiology Cell Physiol Biochem 2016;39:481-490

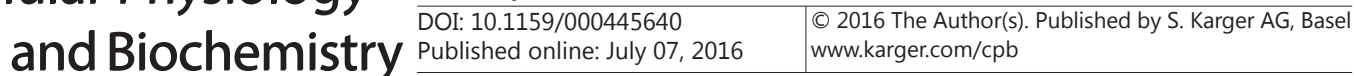

Pan et al.: Verteporfin can Reverse the Paclitaxel Resistance without Photoactivation through Inhibiting YAP Expression

cells and incubated for $16 \mathrm{~h}$. Then the non-invading cells on the upper membrane surface were removed with a cotton tip, and the cells which passed through the filter were fixed with $4 \%$ paraformaldehyde and stained with hematoxylin. The number of invaded cells was counted in ten randomly selected high power fields under microscope. Data presented are representative of three individual wells.

\section{Isobolographic analysis}

To investigate the interaction of verteporfin with the paclitaxel, an isobolographic analysis was performed according to Tallarida. The $\mathrm{IC}_{50}$ values of each drug were calculated by non-linear regression analysis of the log dose-response curve. The interaction between paclitaxel and verteporfin was assessed by the data from the combination therapy of paclitaxel and verteporfin. The $\mathrm{IC}_{50}$ of mixture $\left(\mathrm{IC}_{50 \text { mix }}\right)$ was obtained by the Determination of drug resistance before. Theoretical additive $\mathrm{IC}_{50}$ values $\left(\mathrm{IC}_{50 \mathrm{add}}\right.$ ) were obtained for each combination using the equation:

$\mathrm{IC}_{50 \text { add }}=\mathrm{f}(\mathrm{PTX})+(1-\mathrm{f})(\mathrm{VP})$, where PTX represents the $\mathrm{IC}_{50}$ of Paclitaxel, VP is the $\mathrm{IC}_{50}$ of Verteporfin and $\mathrm{f}$ denotes the fraction of the corresponding $\mathrm{IC}_{50}$ in the drug mixture (in the present study, $\mathrm{f}=0.5$ ).

Isobolograms were constructed according to Tallarida [20]. Significant differences between theoretical and experimental $\mathrm{IC}_{50}$ values were assessed using Student's t-test for independent means: when $\mathrm{IC}_{50}$ add is significantly higher than $\mathrm{IC}_{50 \text { mix' }}$ the combination has a synergistic interaction. The magnitude of the interaction $(\gamma)$ was calculated using the equation:

$\gamma=\mathrm{a} / \mathrm{PTX}+\mathrm{b} / \mathrm{VP}$, where PTX and VP represent the $\mathrm{IC}_{50}$ of each drug (paclitaxel and verteporfin, respectively) alone, and $\mathrm{a}$ and $\mathrm{b}$ are the amounts of each drug (paclitaxel and verteporfin, respectively) in the combination (obtained from the $\mathrm{IC}_{50 \text { mix }}$ ). If $\gamma=1$, the interaction is considered additive; if $\gamma<1$, it is synergistic; and if $\gamma>1$, the interaction is antagonistic [21].

\section{Statistical analysis}

All quantified data were expressed as mean values \pm standard error (mean \pm SE). The Student's t-test for non-paired replicates was used to identify statistically significant differences between treatment means. Group variability and interaction were compared using either one-way or two-way ANOVA followed by Bonferroni's post-tests to compare replicate means. Significance was accepted at $\mathrm{P}<0.05$.

\section{Results}

YAP is over-expressed in chemo-resistant subline and confers PTX resistance to HCT-8/T cells

Over-expression of YAP is thought to account for the PTX resistance subline. Beside this, activation of YAP has been considered in a variety of tumor cells and can induce drug resistance to PTX treatment. Western blotting and confocal showed a higher proportion of YAP over-expression in HCT-8/T cells compared with HCT-8 cells (Fig. 1A, B). In addition, the few percentage of HCT-8 cells which were survived after PTX treatment, exhibited higher YAP expression than normal HCT-8 cells (Fig. 1B). These results promoted the expression of YAP are positively correlated with PTX resistance in human colon cancer cells. In order to investigate the sensitivity of the cell lines to PTX, we used WST-1 assay to detect the cytotoxicity of PTX on HCT-8 and HCT-8/T cells. The inhibition curves indicated that PTX inhibited the growth of HCT-8 and HCT-8/T cells in a dose-dependent manner with the IC ${ }_{50}$ values of PTX for the HCT-8 and HCT-8/T cells were 3.49 and $14.91 \mu \mathrm{M}$, respectively (Table 1). The RF is an important measure which the value of the HCT-8/T subline was 4.27, revealed the cell subline achieved a high degree of resistance to PTX (Fig. 1C).

YAP over-expression could induce the PTX resistance of HCT-8 cells while knockdown of YAP could reduce this resistance

To confirm the relationship between YAP and PTX resistance, we firstly over-expressed YAP in YAP-low/PTX-sensitive HCT-8 cells (Fig. 2A), using plasmids expressing His-tagged YAP. Obviously, over-expression of YAP in HCT-8 cells significantly reduced its drug-sensitivity to PTX (Fig. 2B). Secondly, we knocked down YAP gene in YAP-high/PTX resistant HCT-8/T 


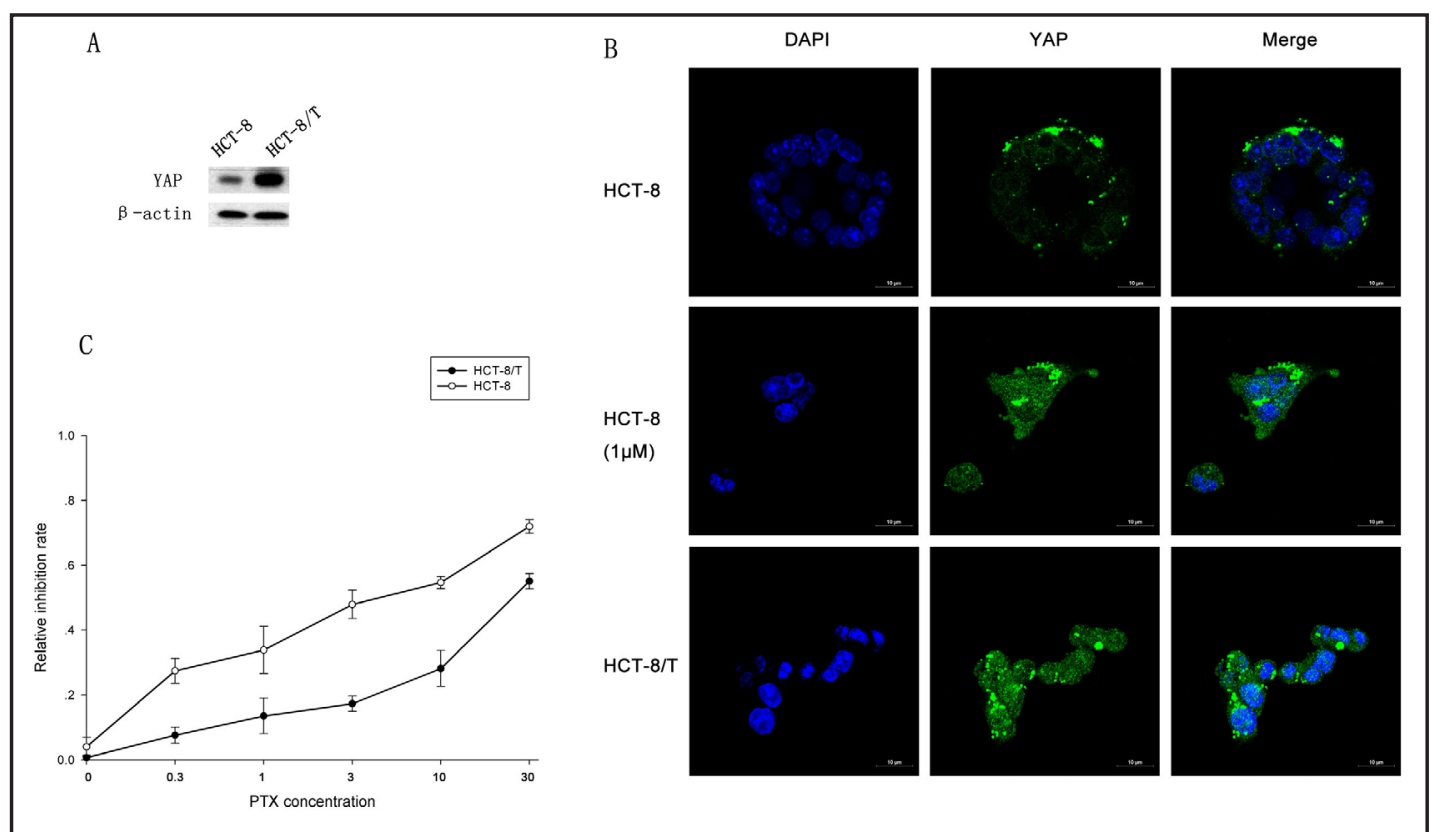

Fig. 1. YAP is over-expressed in chemo-resistant subline and confers PTX resistance to HCT-8/T (A) Western blot analysis was performed to confirm the YAP expression in HCT-8/T and HCT-8 cells. The results showed that YAP expression was significant higher in HCT-8/T cells compared with HCT-8 cells. (B) The Immunofluorescence result indicated that few percentage of HCT-8 cells which were survived after PTX treatment exhibited higher YAP expression than the normal HCT-8 cells and higher proportion of YAP over-expression in HCT-8/T cells compared with HCT-8 cells. (C) WST-1 assay showed PTX resistant cell subline HCT-8/T achieved a high degree of resistance to PTX.

Table 1. The effects of VP on IC50 value of PTX in HCT-8 and HCT-8/T cells

\begin{tabular}{lccc}
\hline Group & VP Concentration $(\mu \mathrm{M})$ & $\mathrm{IC}_{50}$ of PTX $(\mu \mathrm{M})$ & $\mathrm{RF}$ \\
\hline HCT-8 & & 3.49 & 1 \\
HCT-8/T Control & 3 & 14.91 & 4.27 \\
HCT-8/T VP & 12 & 2.29 & 0.66 \\
& & 1.73 & 0.49 \\
\hline
\end{tabular}

cells by using siRNAs (Fig. 2C). Correspondingly, YAP silencing in HCT-8/T cells sensitized their response to PTX treatments (Fig. 2D). Taken together, these results strongly confirmed that YAP is a biomarker for the resistant of colon cancer cells to PTX.

VP reduced the PTX resistance on HCT-8/T cells without light activation by inhibiting YAP and combination therapy with VP and PTX showed synergism on inhibition of YAP and cytotoxicity to HCT-8/T

Since VP has been recognized as an effective YAP inhibitor, we supposed whether VP could reduce the PTX resistance on HCT-8/T cells by inhibiting YAP or not. Western blotting results indicated that VP inhibited YAP in a dose-dependent manner (Fig. 3A), As PTX resistant cell subline HCT-8/T is YAP over-expressed, we supposed whether inhibition of YAP by VP could reverse the resistance on HCT-8/T. WST-1 assay showed the inhibition of cells which were treated with PTX alone or in combination with two different concentrations of VP $(3 \mu \mathrm{M}$ and $15 \mu \mathrm{M})$ had a significant difference (Fig. 3B). Western blotting also showed a corresponding result that resistance-associated protein YAP and it's downstream like Cyr61 was inhibited by combination therapy with VP and PTX (Fig. 3C). Synergism is often used to assess whether the combination of the two drugs would play better results. Correspondingly,

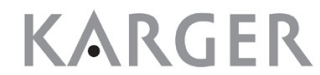


A

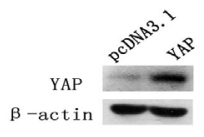

C

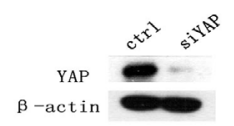

B
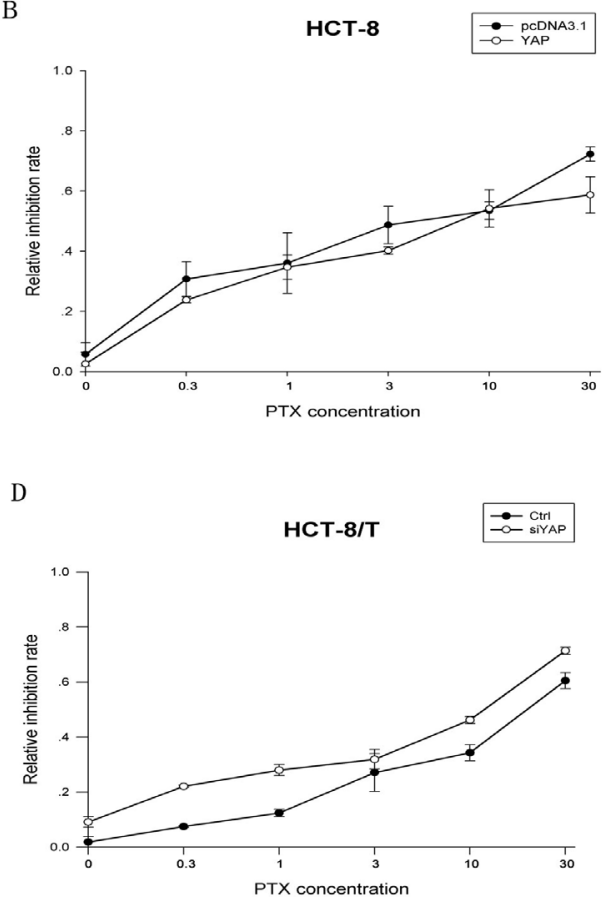

Fig. 2. YAP over-expression could induce the PTX resistance of HCT-8 cells while YAP silencing could reduce this resistance. (A) Western blotting showed that YAP was over-expressed in YAP-low/PTX-sensitive HCT-8 cells, using plasmids expressing His-tagged YAP. (B) WST-1 assay indicated that over-expression of YAP in HCT-8 cells significantly reduced its drug-sensitivity to PTX. (C) Western blotting showed that YAP was knocked down in YAP-high/PTX-resistant HCT-8/T cells, using YAP siRNA. (D) WST-1 assay indicated knocked down of YAP in HCT-8/T cells sensitized their response to PTX treatments.

VP and PTX exhibited good synergy on cytotoxicity to HCT-8/T via isobolographic analysis (Fig. 3D), which the magnitude of the interaction $(\gamma)$ was about 0.60 , respectively. The $\mathrm{IC}_{50}$ values of the control and experiment sets had a significant difference, too (Table 1). Confocal also showed that YAP was further suppressed by combination therapy (Fig. 3E).

VP and PTX combination therapy affected the invasion and colony formation ability and induce apoptosis on HCT-8/T cells

As combination therapy with VP and PTX caused a significantly better cytotoxicity on HCT-8/T cells than treat with PTX alone by effectively inhibition of YAP, we suggested the depletion of YAP in HCT-8/T cell could reduce the invasion and proliferation ability. Transwell assay and colony formation assay indicated that the viability of HCT-8/T cells was significantly inhibited by combination therapy with VP and PTX (Fig. 4A, B, C). Correspondingly, combination therapy with VP and PTX induced apoptosis by the regulation of Bcl-2 families (Fig. 4D).

\section{Discussion}

PTX is one of the most frequently applied agent in cancer chemotherapy regimens. Nevertheless, the drug resistance caused by multiple chemotherapy greatly restricts its use in clinics. Research of the PTX resistance mechanisms in cancer cells such as colon cancer 
Fig. 3. VP reduced the PTX-resistance on HCT-8/T cells by inhibiting YAP expression and combination therapy with VP and PTX showed synergism on inhibition of YAP and cytotoxicity to HCT-8/T. (A) Western blotting indicated VP inhibited YAP in a dose-dependent manner. (B) WST-1 assay showed the inhibition of cells which were treated with PTX alone or in combination with two different concentrations of VP (LV=3 $\mu \mathrm{M}$ and $\mathrm{HV}=$ $15 \mu \mathrm{M}$ ) had a significant difference. (C) Western blotting showed that and Cyr61 were inhibited by combination therapy with VP and PTX. (D) VP and PTX exhibited good synergy on cytotoxicity to HCT-8/T. (E) Confocal showed that YAP was further suppressed by combination therapy.

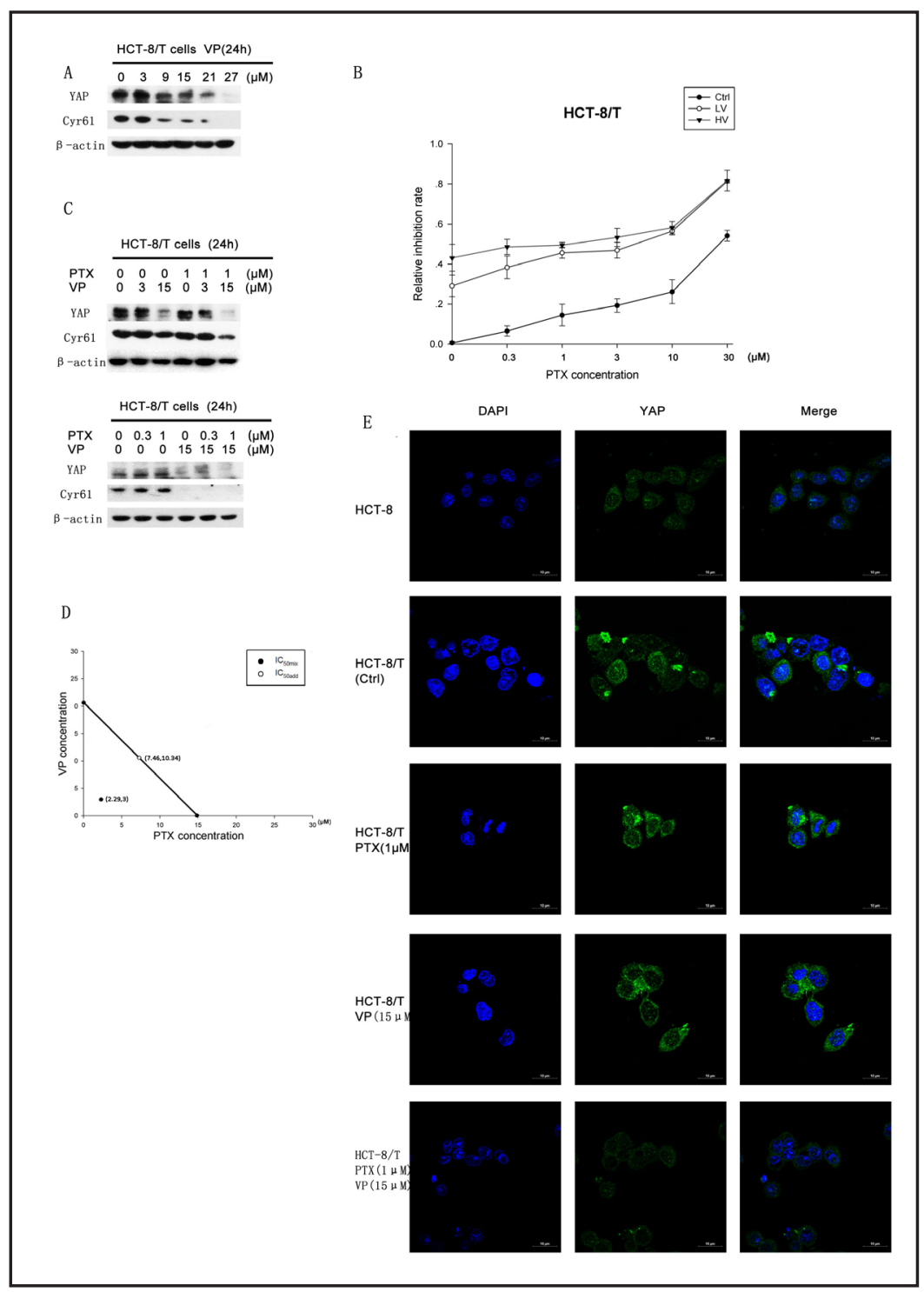

and discovery of new resistant reversal drugs that targeting resistance biomarkers is an crucial field for researchers $[22,23]$.

Previous research has reported that over-expression of YAP promotes PTX resistance in ovarian cancer cells [24]. Accordingly, we suppose YAP to play a similar character in colon cancer cells and inhibition of YAP could reverse the PTX resistance. In the present study, we found YAP was significantly increased in HCT-8/T cells compared with HCT-8 cells. Interestingly, very small proportion of HCT-8 cells which were survived after PTX treatment showed a higher expression of YAP than the expression in the normal HCT-8 cells. The $\mathrm{IC}_{50}$ of HCT-8/T treated with PTX is higher than $\mathrm{IC}_{50}$ of HCT-8 as it should. To further confirm the relationship between YAP and PTX resistance, over-expression of YAP by transfection directionally enhanced the expression level of YAP, resulting in the PTX resistance on HCT-8 cells. Correspondingly, suppression of YAP by siRNA effectively inhibited YAP expression, resulting in the PTX sensitivity on HCT-8/T cells. These results indicated that over-expression of YAP in colon cancer cells will induce the PTX resistance and depletion of YAP can reverse it.

VP was recently reported that could inhibit YAP expression without light activation by interfering with the YAP-TEAD growth pathway since it has been widely and safely used as a photosensitizer in PDT for neovascular macular degeneration as well as treatment of 
Fig. 4. VP and PTX combination therapy affected the invasion and colony formation ability and induce apoptosis on HCT-8/T cells. (A) colony formation indicated that the viability of HCT-8/T was significantly inhibited by combination therapy with either two different concentration of VP (LV $=3 \mu \mathrm{M}$ and $\mathrm{HV}$ $=15 \mu \mathrm{M}$ ) and PTX. (B, C) Transwell assay showed a significant difference of the viability which HCT-8/T was treated by PTX alone or by combination therapy with either two different concentration of VP (LV $=3 \mu \mathrm{M}$ and $\mathrm{HV}=15$ $\mu \mathrm{M}$ ) and PTX. (D) Combination therapy with VP and PTX induced apoptosis by regulation of the Bcl-2 families.

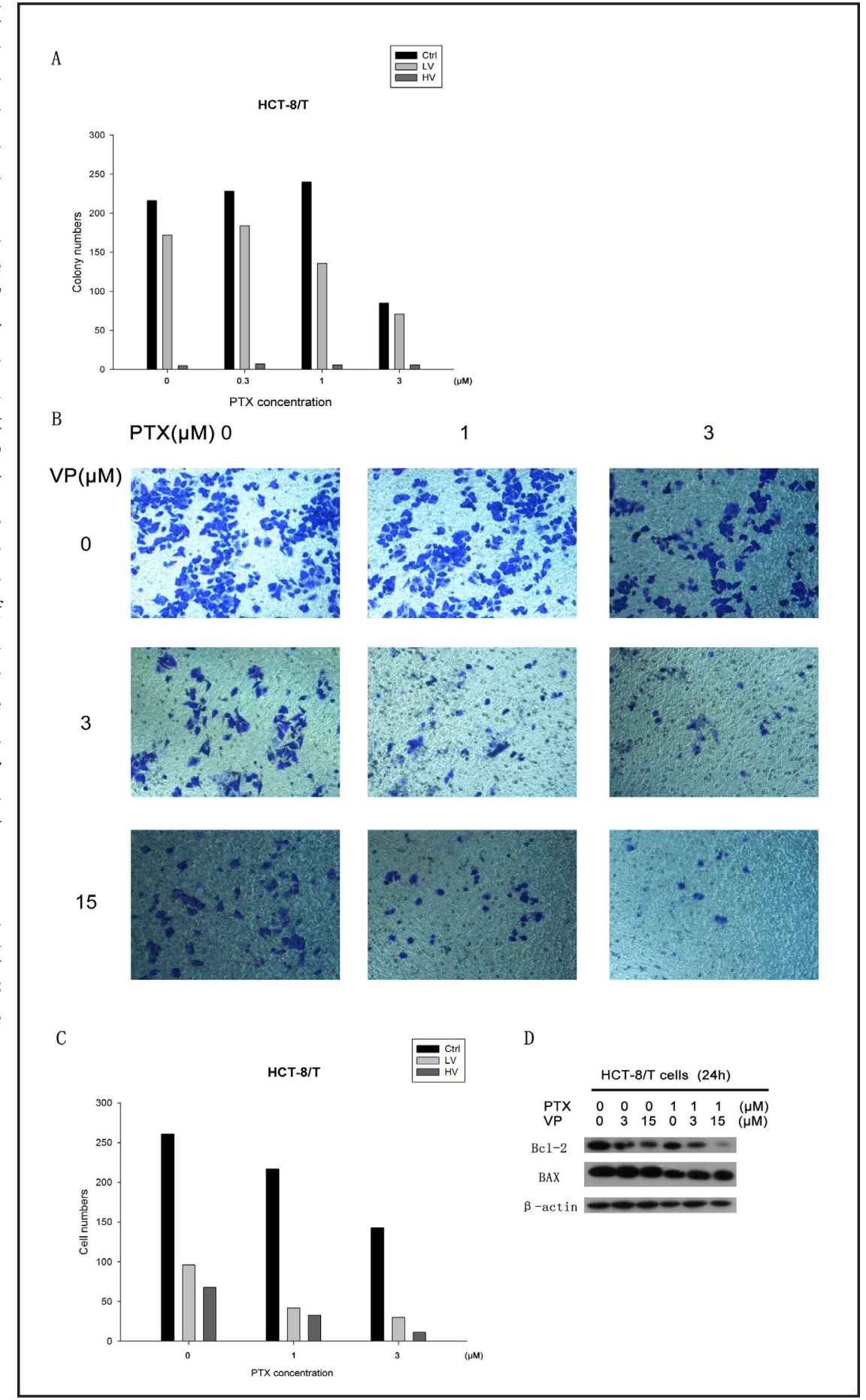

several human tumors [19]. Analyzing proteolytic profiles of the YAP in the presence of VP has shown that VP binds to YAP and enhances the accessibility of trypsin to YAP, presumably by changing the conformation of YAP [25]. Thus, we supposed VP could reverse the PTX resistance by inhibiting the expression of YAP. In our study, we found VP could effectively inhibit YAP and its down-stream. The PTX resistance index was significantly decreased by combination therapy with PTX and both concentrations of VP. Correspondingly, cell viabilities regulated by YAP were also suppressed by the combination therapy. 


\section{Conclusions}

Verteporfin can reverse the paclitaxel resistance induced by YAP over-expression in HCT-8/T cells without photoactivation through inhibiting YAP expression.

\section{Acknowledgments}

This work was supported by the Priority Academic Program Development of Jiangsu Higher Education Institutions (PAPD), NSFC for Talents Training in Basic Science (Grant Nos. J1103507, J1210025), the Scientific Research Foundation for the Returned Overseas Chinese Scholars, State Education Ministry (SRF for ROCS, SEM, 2015311).

\section{Disclosure Statement}

All authors declare no financial competing interests.All authors declare no non-financial competing interests.

\section{References}

1 De Marco MF, Janssen-Heijnen ML, van der Heijden LH, Coebergh JW: Comorbidity and colorectal cancer according to subsite and stage: a population-based study. Eur J Cancer 2000;36:95-99.

2 Siegel R, Ma J, Zou Z, Jemal A: Cancer statistics, 2014. CA Cancer J Clin 2014;64:9-29.

3 Odze RD, Brien T, Brown CA, Hartman CJ, Wellman A, Fogt F: Molecular alterations in chronic ulcerative colitis-associated and sporadic hyperplastic polyps: a comparative analysis. Am J Gastroenterol 2002;97:1235-1242.

4 McCulloch M, Broffman M, van der Laan M, Hubbard A, Kushi L, Abrams DI, Gao J, Colford JM, Jr:: Colon cancer survival with herbal medicine and vitamins combined with standard therapy in a whole-systems approach: ten-year follow-up data analyzed with marginal structural models and propensity score methods. Integr Cancer Ther 2011;10:240-259.

5 D'Antona L, Amato R, Talarico C, Ortuso F, Menniti M, Dattilo V, Iuliano R, Gigliotti F, Artese A, Costa G, Schenone S, Musumeci F, Abbruzzese C, Botta L, Trapasso F, Alcaro S, Paggi MG, Perrotti N: SI113, a specific inhibitor of the Sgk1 kinase activity that counteracts cancer cell proliferation. Cell Physiol Biochem 2015;35:2006-2018.

6 Zhang K, Qin H, Pan F, Liu E, Liang H, Ruan Z: Nedaplatin or oxaliplatin combined with paclitaxel and docetaxel as first-line treatment for patients with advanced non-small cell lung cancer. Med Sci Monit 2014;20:2830-2836.

7 DiPaola RS, Rubin E, Toppmeyer D, Eid J, Butzbach D, Dvorzhinski D, Capanna T, Cairdella M, Shih JW, Goodin S, Todd MB: Gemcitabine combined with sequential paclitaxel and carboplatin in patients with urothelial cancers and other advanced malignancies. Med Sci Monit 2003;9:PI5-11.

8 Zhang Y, Li H, Wang H, Su F, Qu R, Yin D, Dai J, Li Y, Chen X: Syl611, a novel semisynthetic taxane derivative, reverses multidrug resistance by $\mathrm{p}$-glycoprotein inhibition and facilitating inward transmembrane action. Cancer Chemother Pharmacol 2010;66:851-859.

9 Chen XX, Lai MD, Zhang YL, Huang Q: Less cytotoxicity to combination therapy of 5-fluorouracil and cisplatin than 5-fluorouracil alone in human colon cancer cell lines. World J Gastroenterol 2002;8:841-846.

10 Liu AM, Xu Z, Luk JM: An update on targeting Hippo-YAP signaling in liver cancer. Expert Opin Ther Targets 2012;16:243-247.

11 Hong L, Cai Y, Jiang M, Zhou D, Chen L: The Hippo signaling pathway in liver regeneration and tumorigenesis. Acta Biochim Biophys Sin (Shanghai) 2015;47:46-52.

12 Steinhardt AA, Gayyed MF, Klein AP, Dong J, Maitra A, Pan D, Montgomery EA, Anders RA: Expression of Yes-associated protein in common solid tumors. Hum Pathol 2008;39:1582-1589. 


\section{Cellular Physiology Cell Physiol Biochem 2016;39:481-490 \begin{tabular}{ll|l} 
DOI: 10.1159/000445640 & $\begin{array}{l}\text { O 2016 The Author(s). Published by S. Karger AG, Basel } \\
\text { www.karger.com/cpb }\end{array}$
\end{tabular}}

Pan et al.: Verteporfin can Reverse the Paclitaxel Resistance without Photoactivation through Inhibiting YAP Expression

13 George NM, Day CE, Boerner BP, Johnson RL, Sarvetnick NE: Hippo signaling regulates pancreas development through inactivation of Yap. Mol Cell Biol 2012;32:5116-5128.

14 Fujimoto D, Ueda Y, Hirono Y, Goi T, Yamaguchi A: PAR1 participates in the ability of multidrug resistance and tumorigenesis by controlling Hippo-YAP pathway. Oncotarget 2015;6:34788-34799.

15 Ivery MT, Le T: Modeling the interaction of paclitaxel with beta-tubulin. Oncol Res 2003;14:1-19.

16 Joo Y, Schumacher B, Landrieu I, Bartel M, Smet-Nocca C, Jang A, Choi HS, Jeon NL, Chang KA, Kim HS, Ottmann C, Suh YH: Involvement of 14-3-3 in tubulin instability and impaired axon development is mediated by Tau. FASEB J 2015;29:4133-4144.

17 Jinawath N, Vasoontara C, Yap KL, Thiaville MM, Nakayama K, Wang TL, Shih IM: NAC-1, a potential stem cell pluripotency factor, contributes to paclitaxel resistance in ovarian cancer through inactivating Gadd45 pathway. Oncogene 2009;28:1941-1948.

18 Zhang H, Ramakrishnan SK, Triner D, Centofanti B, Maitra D, Gyorffy B, Sebolt-Leopold JS, Dame MK, Varani J, Brenner DE, Fearon ER, Omary MB, Shah YM: Tumor-selective proteotoxicity of verteporfin inhibits colon cancer progression independently of YAP1. Sci Signal 2015;8:ra98.

19 Brodowska K, Al-Moujahed A, Marmalidou A, Meyer Zu Horste M, Cichy J, Miller JW, Gragoudas E, Vavvas DG: The clinically used photosensitizer Verteporfin (VP) inhibits YAP-TEAD and human retinoblastoma cell growth in vitro without light activation. Exp Eye Res 2014;124:67-73.

20 Tallarida RJ: An overview of drug combination analysis with isobolograms. J Pharmacol Exp Ther 2006;319:1-7.

21 Muller LG, Stolz ED, Betti AH, Herzfeldt V, Rates SM: Synergistic interaction between diene valepotriates from Valeriana glechomifolia Meyer (Valerianaceae) and classical antidepressants: an isobolographic analysis. J Pharm Pharmacol 2015;67:1008-1016.

22 Chou TC, Guan Y, Soenen DR, Danishefsky SJ, Boger DL: Potent reversal of multidrug resistance by ningalins and its use in drug combinations against human colon carcinoma xenograft in nude mice. Cancer Chemother Pharmacol 2005;56:379-390.

23 Yun M, Lee D, Park MN, Kim EO, Sohn EJ, Kwon BM, Kim SH: Cinnamaldehyde derivative (CB-PIC) sensitizes chemo-resistant cancer cells to drug-induced apoptosis via suppression of MDR1 and its upstream STAT3 and AKT signalling. Cell Physiol Biochem 2015;35:1821-1830.

24 Xia Y, Chang T, Wang Y, Liu Y, Li W, Li M, Fan HY: YAP promotes ovarian cancer cell tumorigenesis and is indicative of a poor prognosis for ovarian cancer patients. PLoS One 2014;9:e91770.

25 Liu-Chittenden Y, Huang B, Shim JS, Chen Q Lee SJ, Anders RA, Liu JO, Pan D: Genetic and pharmacological disruption of the TEAD-YAP complex suppresses the oncogenic activity of YAP. Genes Dev 2012;26:13001305. 